\title{
Relações Conjugais e Parentais: Uma Comparação entre Famílias de Classes Sociais Baixa e Média
}

\author{
Marcela Pereira Braz ${ }^{1}$ \\ Maria Auxiliadora Dessen² \\ Nara Liana Pereira Silva \\ Universidade de Brasilia
}

\begin{abstract}
Resumo
É importante estudar as inter-relações entre as relações parentais e maritais para a compreensão do desenvolvimento e o ajustamento social de crianças. O objetivo deste estudo é descrever aspectos da qualidade das relações parentais e maritais de 14 famílias de classes média e baixa, compostas por pai, mãe e criança-alvo na faixa etária de 4-5 anos. Um questionário sobre dados sócio-demográficos, estrutura familiar, modos de vida e divisão de tarefas domésticas foi respondido pelas mães e uma entrevista semi-estruturada foi conduzida com mães e pais, separadamente, incluindo questões sobre satisfação marital, conflito, coalizão, valores e crenças sobre casamento e educação de filhos e suas influências nas interações genitores-criança. Os resultados indicam que uma boa relação marital favorece o compartilhamento de tarefas domésticas e práticas de educação entre maridos e esposas e promove o desenvolvimento de sentimentos de segurança em suas crianças. Os dados são discutidos em termos das influências mútuas entre as relações maritais e parentais, levando em consideração as similaridades e as diferenças entre as famílias de classes média e baixa.
\end{abstract}

Palavras-chave: Relações conjugais; relações parentais; crianças pré-escolares; família.

\section{Marital and Parental Relationships: A Comparison of Middle and Working Class Families}

\begin{abstract}
It is important to study the interrelatedness between marital and parental relationships in order to understand children's social adjustment and development. Therefore, this study aims to describe aspects of the quality of marital and parental relationships from Brazilian working and middle class families. Fourteen families consisting of father, mother, and target preschool children at the age of 4-5 years were selected to participate in this study. A questionnaire on social-demographic data, family structure, lifestyles, and division of home tasks was answered by mothers. A semi-structured interview was conducted with mothers and fathers, separately, including questions on marital satisfaction, conflict, coalition, values and beliefs on marriage and parenting, and their influence on parents-child interactions. The results indicate that a good marital relationship fosters sharing domestic tasks and childrearing practices between wives and husbands and promotes the development of security feelings in their children. The discussion is based on the differences between working and middle class families in terms of mutual influences between both kinds of relationships.

Keywords: Marital relationships; parental relationships; preschool children; family.
\end{abstract}

Há consenso na literatura sobre a existência de uma forte correlação entre a qualidade das relações conjugais e parentais (Belsky, 1981, 1984; Brody, Pellegrini \& Sigel, 1986; Erel \& Burman, 1995; Gottman, 1993, 1998; Kreppner \& Ullrich, 1998). O relacionamento marital tem sido apontado, recentemente, como um fator preponderante para a qualidade de vida das familias, particularmente no que tange às relações que pais e mães mantêm com suas crianças. O ajustamento conjugal, as formas de comunicação e as estratégias de resolução de conflitos empregadas pelo casal influenciam o desenvolvimento de padrões de cuidado dos filhos e a qualidade das relações entre os genitores e suas crianças. Por exemplo, casamentos saudáveis proporcionam mais suporte aos cônjuges que relações maritais insatisfatórias e o apoio emocional dos pais às mães favorece o desenvolvimento saudável dos filhos (Belsky, 1981, 1984; Erel \& Burman, 1995; Gottman, 1993, 1998; Gottman \& Silver, 1999).

A literatura aponta inúmeros prejuízos diretos e indiretos, tanto para os cônjuges, como para seus filhos, provocados por uma relação

${ }^{1}$ Este artigo foi escrito com base na dissertação de Mestrado apresentada ao Instituto de Psicologia da Universidade de Brasilia pela primeira autora, sob a orientação da segunda. As autoras agradecem ao CNPqo apoio concedido.

${ }^{2}$ Endereço para correspondência: Universidade de Brasilia, Instituto de Psicologia, Laboratório de Desenvolvimento Familiar, Campus Universitário Darcy Ribeiro, 70910 900, Brasilia, DF. Fone: (61)33072625, Ramal 417/409.E-mail:dessen@unb.br conjugal insatisfatória (Gottman, 1993, 1998; Gottman \& Katz, 1989). As conseqüências negativas das relações maritais insatisfatórias, e possivelmente do divórcio ou da separação do casal, incluem o aumento do risco de os cônjuges apresentarem psicopatologias, de estarem envolvidos em acidentes automobilísticos, de exposição à incidência de doenças físicas, de cometerem suicídio, homicídio ou atos de violência, de mortalidade em função de doenças em geral, entre outras. Segundo Gottman (1998), as influências negativas produzidas nas crianças, em conseqüência de relações conjugais insatisfatórias, são variadas, incluindo desde problemas de saúde, depressão, baixa competência social e baixa performance acadêmica, até vários outros distúrbios de conduta correlacionados. Por exemplo, Lee e Gotlib (1994) relatam que genitores de crianças hiperativas apresentam um ajustamento marital fraco e uma elevada taxa de separação e divórcio.

Portanto, há fortes evidências dos prejuízos causados pelas disfunções familiares no desenvolvimento dos filhos, isto é, há uma correlação positiva entre os distúrbios na relação conjugal e/ou dos genitores enquanto indivíduos e os problemas de comportamento da criança (Bond \& McMahon, 1984; Cox, Owen, Lewis \& Henderson, 1989; Deal, Hogan, Bass, Hetherington \& Clingempeel, 1999; Emery, 1982; Goldberg \& Easterbrooks, 1984; Gottman, 1993, 1998; Radke-Yarrow, 
Richters \& Wilson, 1988; Sroufe \& Fleeson, 1988). Brody e colaboradores (1986) realizaram uma pesquisa para examinar a associação entre a qualidade das relações maritais e as interações dos genitores com suas crianças de idade escolar. Para os autores, os cônjuges que ofereciam suporte mútuo e cujas relações maritais eram satisfatórias apresentavam maior sensibilidade em seu papel parental que os cônjuges cujas relações eram insatisfatórias. Os genitores, por sua vez, mantinham interações também satisfatórias com seus filhos e estes eram igualmente responsivos ao pai e à mãe. Entretanto, as mães insatisfeitas tendiam a compensar seus filhos, sendo mais responsivas e demandando mais de suas crianças; já os pais emitiam comportamentos mais negativos e intrusivos em relação aos filhos, tendo, portanto, pais e mães reações diferentes em relação às suas crianças. Em contraposição a isto, os cônjuges satisfeitos tendiam a mostrar coerência entre si e em relação aos seus filhos.

Goldberg e Easterbrooks (1984), investigando a importância da qualidade das relações maritais para as atitudes e comportamentos parentais e para o desenvolvimento de crianças pequenas em familias com dois genitores, concluíram que o ajustamento e a harmonia do casal tinham efeitos no comportamento da criança. Nesse estudo, a harmonia marital estava associada com afeto positivo e com boa orientação por parte dos genitores durante atividades de resolução de tarefa. Já, a satisfação conjugal estava associada com relações de apego seguro entre os genitores e sua criança, enquanto que relações parentais inseguras predominavam entre cônjuges com ajustamento marital fraco. Os autores mostraram que tanto os efeitos diretos (Ex.: ajustamento conjugal do marido influenciando seu modo de ser pai), quanto os indiretos (Ex.: satisfação marital da esposa e sua influência na maneira de seu marido ser pai) estavam associados ao funcionamento conjugal, às atitudes, às percepções e aos comportamentos parentais.

Gottman e Katz (1989), por sua vez, mostraram uma clara associação entre a discórdia marital e a saúde física da criança e suas relações com seus pares. O estresse marital pode dificultar o desenvolvimento das relações sociais da criança e aumentar sua susceptibilidade a doenças fisicas. Ao interagir com a criança, ensinando uma tarefa, os genitores que apresentavam insatisfação conjugal e tinham uma defesa fisiológica abaixo do esperado caracterizavam-se por um estilo parental frio, não responsivo e irritadiço. Este estilo de interação foi associado tanto à raiva e à falta de obediência e submissão da criança, quanto aos elevados níveis de hormônios relacionados ao estresse, encontrados entre os genitores. Filhos de casais insatisfeitos tendiam a brincar menos, a apresentar uma freqüência maior de interações negativas com seus pares e a ter uma saúde pior que as demais. As crianças que expressavam raiva e insatisfação tendiam a brincar menos com seus pares e a ter mais dificuldades para manejar tais sentimentos, estando em constante estado de vigilância e defesa da raiva e da agressividade.

Em síntese, os estudos mostram que a relação marital tem um papel fundamental tanto para as relações estabelecidas entre os genitores e seus filhos, como para o desenvolvimento de suas crianças, em geral. Relações conjugais satisfatórias fornecem apoio para maridos e esposas, o que dá suporte a relações parentais de boa qualidade, isto é, casamentos 'bons' estão ligados positivamente com a sensibilidade parental e casamentos 'ruins', à insensibilidade dos genitores e, conseqüentemente, a um desenvolvimento infantil bem ou mal ajustado, respectivamente. A influência das relações maritais nas relações parentais vêm sendo destacada tanto na psicologia do desenvolvimento familiar, como na clínica (Bigras \& Paquete, 2000; Bond \& McMahon, 1984; Carter \& McGoldrick, 1980/1995; Emery, Fincham, \& Cummings, 1992; Erel \& Burman, 1995; Féres-Carneiro, 1998; Grych \& Fincham, 1990; Heavey, Shenk \& Christensen, 1994; Siqueira, Ribeiro \& Duarte, 1999).

A meta-análise conduzida por Erel e Burman (1995) revela a existência de duas grandes hipóteses que associam as relações conjugais às parentais. A primeira hipótese é a de que existe uma correlação positiva entre ambos os tipos de relação. Neste caso, uma relação marital negativa ou conflituosa provoca irritação e desequilíbrio emocional nos cônjuges, o que influencia os seus comportamentos como genitores, tornando-os menos atenciosos e menos sensiveis às suas crianças. O contrário também é verdadeiro, ou seja, uma relação conjugal satisfatória oferece suporte aos cônjuges, favorecendo a manutenção de uma relação positiva com seus filhos. Na segunda hipótese, em que a correlação é negativa ou compensatória, um casamento estressante, por exemplo, pode aumentar a atenção dos pais à criança como uma forma de compensar tanto a falta de afeto e satisfação na relação conjugal como a exposição da criança ao conflito marital. Cônjuges insatisfeitos em suas necessidades de amor e intimidade buscam satisfazê-las na relação com suas crianças. Neste mesmo sentido, uma relação conjugal satisfatória é associada a uma relação parental ruim, pois, nesse caso, a criança é percebida como um empecilho à intimidade do casal.

Segundo Erel e Burman (1995), há fortes argumentos que favorecem a hipótese positiva em contraposição à hipótese negativa ou compensatória. A primeira suposição está fundamentada em dois questionamentos básicos: a) dificilmente se encontraria uma relação verdadeiramente satisfatória entre genitores e filhos, tendo o casal uma relação conjugal insatisfatória; e, b) se houvesse uma aliança positiva entre um dos genitores e a criança, este fato provocaria interações negativas ou conflituosas entre o outro genitor e seu filho, conduzindo a dificuldades nas relações conjugais e parentais. Os autores sugerem que os estudos futuros examinem a correlação entre as relações genitores-criança e o desenvolvimento da criança, incluindo, obrigatoriamente, o impacto da relação marital na relação parental.

Embora haja um crescente interesse dos pesquisadores para investigar a correlação entre as relações conjugais e as parentais, a maioria dos trabalhos tem sido realizada em outros países, com amostras que possuem características culturais, étnicas e sociais diferentes da realidade brasileira. Assim, considerando a escassez de pesquisas sobre o tema, em nosso contexto cultural, e a necessidade de compreender mais profundamente a interdependência entre os subsistemas conjugal e parental em familias brasileiras com crianças pré-escolares, implementamos um estudo com o objetivo de descrever algumas das dimensões das relações parentais e maritais de familias provenientes de classes sociais média e baixa, visando a identificar 
aspectos da inter-relação entre ambos os tipos de relação. Dentre as dimensões, destacamos: a) aspectos demográficos e estrutura familiar; b) qualidade das interações marido-esposa, mãe-criança e pai-criança e das interações estabelecidas pela criança fora do contexto familiar; c) valores, crenças e expectativas parentais sobre o desenvolvimento e a educação dos filhos e sobre as estratégias de socialização empregadas pelos genitores; d) coalizão marital, conflito, satisfação conjugal e valores dos cônjuges sobre o casamento; e, e) interferência dos filhos na relação conjugal e influência da relação conjugal nas relações parentais e, conseqüentemente, no desenvolvimento social dos filhos.

\section{Método}

\section{Participantes}

Participaram do estudo 14 famílias compostas por pai, mãe e crianças pré-escolares, sendo 7 provenientes de classe social baixa e 7 de classe média. A maioria das familias $(85,7 \%)$ residia em cidades satélites do Distrito Federal. A classe social foi definida pelo nível de escolaridade e ocupação dos genitores, renda familiar e local de moradia das familias. As de classe baixa residiam nas cidades satélites de Planaltina $(n=5)$ e Ceilândia $(n=2)$ e as de classe média em Taguatinga $(n=5)$ e no Plano Piloto $(n=2)$. A idade média das crianças alvo era de 5 anos e 5 meses, sendo a maioria $(71,5 \%)$ do sexo masculino. Todas as crianças freqüentavam a pré-escola, com exceção de uma. As 14 familias possuíam um total de 35 filhos, 18 (51,4\%) do sexo masculino e $17(48,6 \%)$ do sexo feminino.

Os genitores, em sua maioria (64,3\%), eram casados legalmente; os demais $(35,7 \%)$ moravam juntos. O tempo de convivência dos cônjuges $(71,6 \%)$ variava de 5 a 15 anos. A idade média das mães era de 32 anos e 4 meses e a dos pais de 36 anos e 3 meses. O nível de escolaridade dos genitores variou de acordo com a classe sócioeconômica. A quase totalidade de pais e mães de classe social baixa $(n=13)$ possuía o ensino fundamental incompleto, com apenas um deles tendo concluído o ensino médio. Dentre os genitores de classe social média, a metade ( $n=7$ ) havia completado o ensino médio, 3 deles o ensino superior e outros 3 estavam ainda cursando o ensino superior. Apenas um pai havia concluído seus estudos pós-graduados. Metade dos participantes trabalhava 8 horas diárias.

As ocupações dos pais eram: militar $(n=3)$, bancário $(n=1)$, técnico judiciário $(n=1)$, técnico administrativo $(n=1)$, técnico em áudio $(n=1)$, autônomo $(n=2)$, trabalhador da construção civil $(n=2)$ e garçom $(n=2)$. Um pai estava desempregado por ocasião da coleta de dados. Quanto às mães, 7 eram donas-decasa, 3 trabalhavam em serviços gerais e as demais trabalhavam como cabeleireira, técnica de enfermagem, bancária e técnica administrativa. Quanto à renda familiar, a maioria das famílias de classe social baixa $(71,5 \%)$ recebia até $\mathrm{R} \$ 600,00$ por mês, correspondendo a 3,3 salários mínimos ${ }^{3}$. Dentre as famílias de classe média, a maior parte $(71,5 \%)$ recebia entre $\mathrm{R} \$ 2.800,00$ e $\mathrm{R} \$ 5.000,00$ mensais, correspondendo a uma variação de 15,5 a 27,7 salários mínimos.

${ }^{3} \mathrm{O}$ salário mínimo vigente à época da coleta de dados era $\mathrm{R} \$ 180,00$.

\section{Procedimentos}

A coleta de dados foi efetuada na própria residência das famílias, consistindo da aplicação de um questionário sóciodemográfico desenvolvido por Dessen (1999), com a finalidade de caracterizar a estrutura e os modos de vida familiar. As mães responderam questões sobre idade, escolaridade, renda familiar, ocupação e estado civil dos genitores, contatos sociais da família, identificação dos responsáveis pelas tarefas rotineiras da casa e dos cuidados com a criança, dentre outras. Um roteiro de entrevista semi-estruturada foi administrado ao pai e à mãe, separadamente, com duração aproximada de 25 a 30 minutos cada uma. Todas as entrevistas foram gravadas em áudio e, posteriormente, transcritas, na íntegra. Foram investigadas 4 dimensões $^{4}$ : a) questões relacionadas à criança alvo do estudo; b) aspectos da relação parental; c) aspectos da relação marital; e, d) a inter-relação entre a relação parental e a relação marital.

O questionário de caracterização do sistema familiar foi tabulado e, para as questões abertas, foram desenvolvidas categorias de análise com base nas respostas fornecidas pelas mães. Já a análise dos dados das entrevistas foi realizada em três momentos: a) transcrição das fitas de áudio; b) desenvolvimento do sistema de categorias; e, c) tabulação dos dados, de acordo com o sistema de categorias definitivo. Isto é, após a transcrição das fitas, foi elaborado um sistema preliminar de categorias que foi revisado e testado objetivando acrescentar, eliminar ou reformular as categorias que não se mostravam apropriadas. Este procedimento foi repetido até que se obteve o sistema definitivo. Os dados das entrevistas foram, então, tabulados segundo a classe social e o relato de pais e mães, separadamente.

\section{Resultados}

Os resultados são descritos em quatro etapas. Primeiramente, apresentamos uma caracterização das famílias, ressaltando os modos de vida peculiares a ambos os tipos de familias (classes média e baixa) e os principais eventos ocorridos particularmente com as crianças. Em seguida, descrevemos aspectos das relações parentais com destaque para a percepção dos genitores quanto ao desenvolvimento da criança alvo e aos seus valores e crenças a respeito da criação de filhos e dos papéis de 'pai' e 'mãe'. Os aspectos da relação marital enfatizam a percepção de cada genitor a respeito de sua própria relação conjugal e de suas crenças a respeito do casamento. Finalmente, apresentamos dados a respeito da inter-relação entre as relações maritais e parentais, priorizando a percepção dos genitores quanto à interferência dos filhos nas relações do casal e do relacionamento conjugal nas relações que eles mantêm com suas crianças.

\section{Dinâmica familiar: Um panorama geral}

As mães são as principais responsáveis pelas atividades relativas ao cuidado dos filhos e pela execução das tarefas domésticas. Elas relataram uma participação intensa nas atividades de dar comida e banho, levar e trazer da escola, orientar dever escolar, levar para atividades de lazer e colocar para dormir. Mesmo quando ambos

\footnotetext{
${ }^{4}$ Para maiores detalhes sobre o roteiro de entrevista, consultar Braz (2002).
} 
os genitores trabalham fora, o cuidado dos filhos fica sob a responsabilidade das mães, embora 27\% delas recorram à ajuda de tios ou tias da criança e $21 \%$ aos serviços de empregadas domésticas. Este elevado engajamento ocorre também em relação aos afazeres domésticos, como arrumar a casa, cozinhar, lavar e passar roupas, fazer compras e orientar empregada doméstica. As mães de classe baixa lavam e passam roupa mais que as mães de classe média, enquanto que estas fazem mais compras que as primeiras (ver Figura 1).

É interessante destacar que $71 \%$ das mães de classe baixa trabalham fora de casa, em contraposição ao mesmo percentual de mães de classe média que não trabalham, embora, conforme depreendido pela Figura 1, as mães de classe baixa se envolvam em afazeres domésticos mais intensamente que as mães de classe média, que contam com a ajuda de empregadas domésticas, que executam grande parte dos afazeres. Já a participação dos pais é menor que a das mães e, no caso dos pais de classe média, também é menor que o engajamento de outras pessoas. Dentre as atividades mais realizadas pelos pais, destacam-se: levar as crianças para atividades de lazer e fazer compras.

Em relação aos principais eventos ocorridos, a maior parte das famílias (64\%) relatou ter passado por algum tipo de dificuldade financeira, particularmente as famílias de classe baixa (78\%), em contraposição às de classe média (22\%). Os problemas financeiros foram associados a quatro motivos: desemprego, renda insuficiente, dívidas e doenças. Os genitores de classe baixa (36\%) foram mais acometidos de desemprego que os de classe média $(22 \%)$ e um número maior de pais $(60 \%)$ que de mães (40\%) ficou desempregado, em algum momento na trajetória de vida das famílias. Quanto à existência de brigas entre o casal, as mães $(79 \%)$ relataram a ocorrência de atritos e conflitos que aconteciam, predominantemente, sem agressões físicas (91\%). Apenas uma mãe relatou haver violência física entre os cônjuges, durante as situações de conflito.

Para pouco mais da metade das mães (57\%), o consumo de álcool pelos membros familiares ocorria apenas em eventos sociais, como festas e reuniões de familia. Apenas um pai relatou beber diariamente, acarretando problemas para a familia. Os problemas com a polícia ou prisão ocorreram em duas familias (14\%), uma de cada classe social, e os envolvidos não eram membros da família nuclear. A Figura 2 apresenta os principais eventos ocorridos durante a trajetória do grupo familiar decorrentes de transições normativas e não-normativas, por classe social.

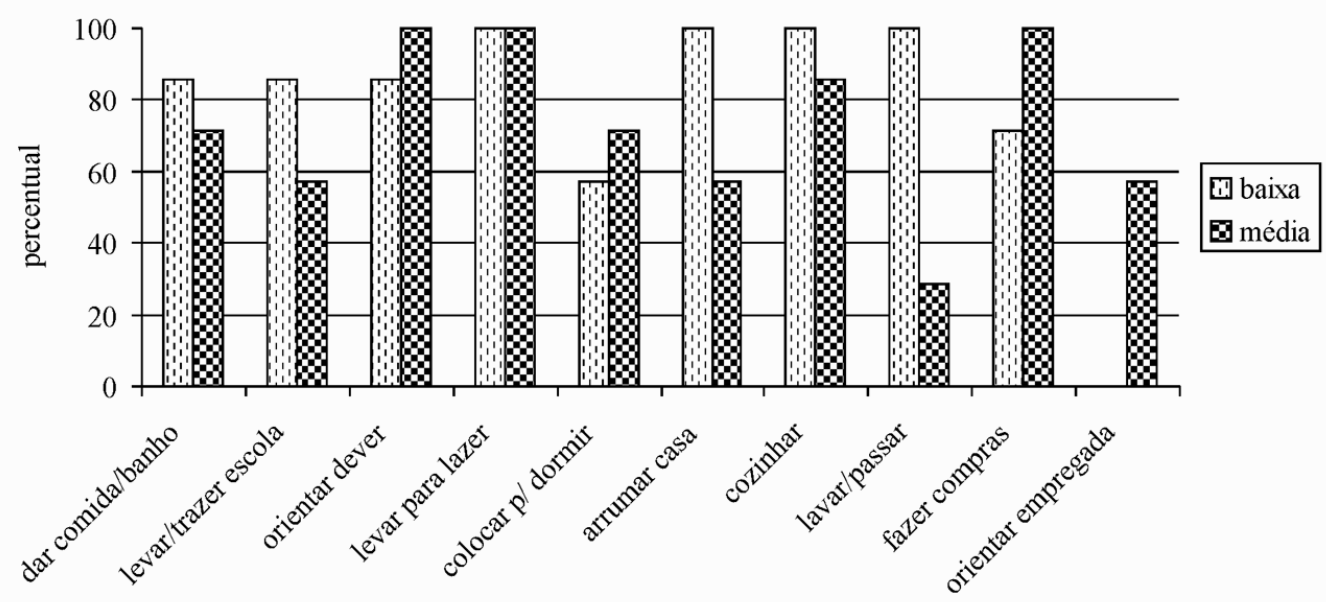

Figura 1. Atividades realizadas por mães de classes baixa e média.

\section{田baixa millédia}

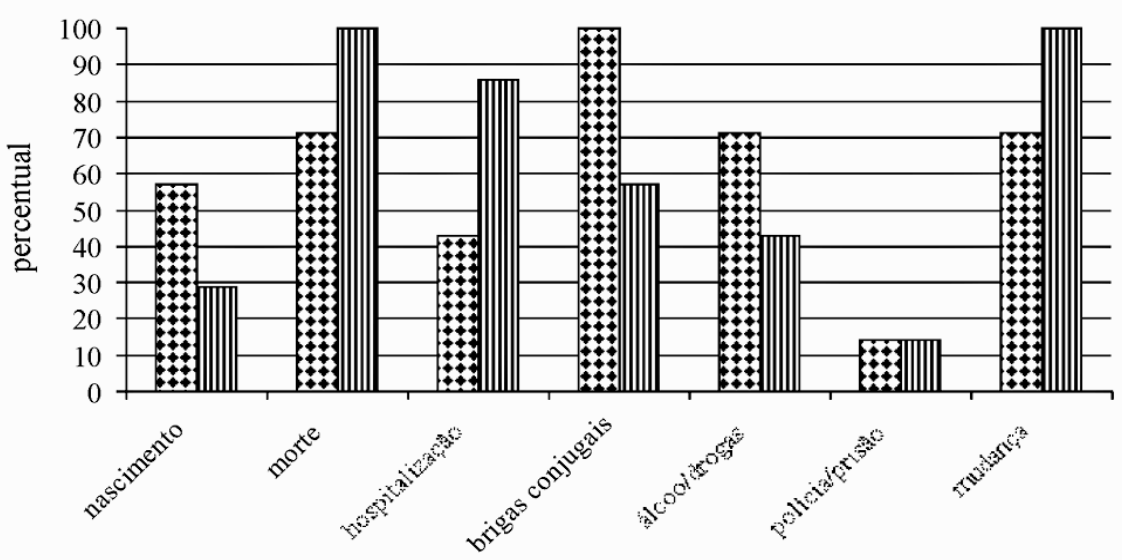

Figura 2. Ocorrência de eventos normativos e não-normativos, por classe social. 


\section{As Relações Parentais}

\section{Como os genitores percebem o desenvolvimento de suas crianças?}

A maioria dos genitores $(86 \%)$ relatou que suas crianças apresentavam desenvolvimento 'normal', 'tranqüilo', 'sem maiores problemas'; porém, 11\% dos genitores de classe média acreditavam que seus filhos tinham um desempenho global acima da média e uma mãe (4\%) de classe baixa mencionou que o desempenho de sua criança estava abaixo de suas expectativas. Setenta e cinco porcento dos genitores acreditam que suas crianças são bem-humoradas, isto é, 'calmas', 'tranqüilas', 'brincalhonas', 'alegres'; 14\% percebem seus filhos como sendo 'mal-humorados', 'irritadiços' e 'emburrados'; e 11\% não fizeram referência ao estado de humor das crianças. A 'afetividade' e a 'sociabilidade' (39\%), a 'passividade/obediência' (27\%) e a 'teimosia/desobediência' (29\%) das crianças alvo foram as características emocionais e comportamentais mais ressaltadas. Alguns pais e mães também mencionaram a 'inteligência/criatividade' (25\%), a 'manha' (18\%), a 'dedicação ao estudo' (14\%), o 'isolamento social' (11\%), a 'agressividade' (11\%), a 'educação/bom comportamento' (11\%), a 'independência' (7\%), a 'dependência' (4\%) e a 'vaidade' (4\%) como características próprias de seus filhos.

Os genitores das duas classes sociais descreveram o relacionamento social de suas crianças de forma diferenciada. Dos 18 que caracterizaram as interações da criança com a mãe como sendo amistosas, 12 eram de classe média e seis de classe baixa. Nove genitores de classe média mencionou a afetividade de seus filhos nas interações com as pessoas em geral, mas apenas dois de classe baixa apresentaram relatos similares. Os pais e as mães pensam diferente sobre o relacionamento fraterno. A maioria das mães (57\%) acredita que as crianças estabelecem interações afetivas positivas com os irmãos, mas somente $21 \%$ dos pais pensam da mesma maneira.

Que valores os genitores transmitem às suas crianças e quais são suas expectativas quanto ao futuro dos filhos?

Os valores relativos à conformidade ${ }^{5}$ mais relatados pelos genitores foram: 'educação/boas maneiras' (50\%), 'respeito' aos mais velhos e às pessoas em geral (46\%), 'valores morais' (39\%) e 'obediência' (32\%). A 'afetividade' (36\%), seguida pela 'justiça', 'religiosidade' e 'honestidade' (18\%) foram os valores humanitários mais referidos. A 'sociabilidade' (32\%) foi destacada dentre os valores relativos à 'autonomia'; os demais - 'autoconfiança', 'competitividade' e 'capacidade' para gerir bens materiais e dinheiro - tiveram apenas uma ocorrência cada.

Para as mães, a educação, o respeito, a afetividade e a obediência são os valores mais importantes a serem transmitidos por elas e seus esposos na educação e criação de seus filhos; para os pais, o que merece maior atenção na formação de suas crianças é ensiná-las a ter valores morais e estimulá-las a dedicar-se ao estudo e às atividades acadêmicas. Com relação à classe social, os respondentes da classe média consideram mais importante transmitir para os filhos a sociabilidade, a afetividade e a obediência. Já os de classe baixa, a educação, o respeito, os valores morais e a dedicação ao estudo.

As expectativas dos genitores quanto ao futuro de seus filhos estão relacionadas à personalidade $(79 \%)$, aos comportamentos $(29 \%)$ e à saúde $(7 \%)$ da criança. O futuro profissional (46\%), as relações

\footnotetext{
${ }^{5}$ Dimensões adaptadas da proposta de Tudge e colaboradores (1999).
}

interpessoais $(36 \%)$ e a aquisição de valores $(32 \%)$ também foram dimensões mencionadas pelos genitores. A maioria dos genitores de classe média $(79 \%)$ espera que seus filhos tenham sucesso profissional e que se sintam satisfeitos com a vida que escolheram (57\%). Enquanto $43 \%$ de pais e mães de classe média esperam que seus filhos se tornem afetivos, apenas 14\% das mães de classe baixa relataram tal característica como esperada para os seus filhos. Para os genitores de classe baixa, ser estudioso (43\%), honesto, trabalhador, responsável e respeitador (43\%) são as características mais desejadas para os seus filhos, no futuro.

\section{Quais são as estratégias de socialização empregadas pelos genitores?}

Os genitores utilizam, basicamente, três tipos de estratégias para socializar seus filhos: a) as de 'correção', aplicadas quando a criança faz algo considerado incorreto; b) as 'neutras', quando ignoram ou não fazem nada diante do comportamento emitido pela criança, seja este considerado correto ou incorreto; e, c) as 'reforçadoras', usadas quando a criança faz algo correto ou aprovado. Os genitores de classes baixa e média diferem quanto ao uso das estratégias de socialização de suas crianças. Dentre as estratégias de 'correção', os genitores de classe média utilizam mais punição verbal (79\%), diálogo (64\%), punição física (43\%), inibição da liberdade $(43 \%)$ e negação de algo desejado (14\%) que os de classe baixa $(50 \%$; 21\%; 36\%; 36\%; 7\%, respectivamente). As demonstrações de 'aprovação' verbal/ emocional também são mais utilizadas pela classe média (93\%) que pela classe baixa $(71 \%)$. O oferecimento de premiação material e o uso de estratégias 'neutras' foram mencionados somente por um pai de classe média e um de classe baixa, respectivamente.

Pais e mães também apresentam distinções no emprego de estratégias de socialização de suas crianças. Os pais (86\%) usam mais punição verbal que as mães (43\%), e estas inibem mais a liberdade $(50 \%)$ e negam algo desejado $(21 \%)$ pelas crianças que os pais ( $28 \% ; 0 \%$, respectivamente). No entanto, a autoridade sobre a criança alvo é exercida tanto pelas mães quanto pelos pais $(95 \%)$ e, eventualmente, pela mãe e um irmão (5\%).

\section{O que é ser um 'bom' pai e uma 'boa' mãe? O que é uma 'boa' e uma 'má' criação de filhos?}

Três grandes grupos de valores definem um 'bom' pai e uma 'boa' mãe, segundo os genitores: a) valores emocionais, que envolvem a afetividade, a bondade e o suporte emocional; b) valores de personalidade e conduta, que incluem o suporte material, a honestidade, a submissão, a participação e a responsabilidade pelo cuidado dos filhos e pelas atividades domésticas; e, c) valores de socialização, englobando a disciplina e a orientação. A distribuição das respostas dos participantes pode ser observada na Figura 3.

Para os participantes de classe baixa, o mais importante é que o pai seja afetivo (64\%); os de classe média acreditam que um bom 'pai' é participativo (57\%), provedor de suporte emocional $(57 \%)$, orientador $(50 \%)$ e disciplinador $(43 \%)$ dos filhos. A maioria das mães $(43 \%)$ valoriza mais um pai provedor de suporte material que os próprios pais $(7 \%)$.

Orientare conduzir (71\%) os filhos, ser afetiva (64\%), participativa (50\%), responsável pelo cuidado dos filhos e pelas atividades domésticas (50\%) e prover suporte emocional (50\%) são qualidades associadas a uma 'boa' mãe, segundo os genitores de classe média. Já 
os de classe baixa, acreditam que a afetividade (57\%) e a habilidade da mãe para disciplinar, impor limites e corrigir os erros (50\%) dos filhos são as características mais importantes em uma 'boa' mãe. $\mathrm{Na}$ opinião das mães, orientar e educar (64\%) e ser afetiva (57\%) e participativa $(50 \%)$ fazem parte do papel de uma 'boa' mãe; para os pais, o aspecto mais importante é a afetividade (64\%) materna.

Os genitores acreditam que uma 'boa' educação deve privilegiar, primeiramente, o acesso à educação informal (64\%), ou seja, pais e mães devem acompanhar, conduzir, orientar e preparar seus filhos para a vida. Em segundo lugar, eles consideram importante usar estratégias disciplinares (54\%), manter um bom relacionamento entre genitores e filhos $(39 \%)$ e transmitir valores morais $(39 \%)$, indicando noções de certo e errado.

Uma 'má' criação de filhos é caracterizada pela ausência e/ou pelo uso inadequado de estratégias disciplinares, ou seja, não corrigir erros e não impor limites ou regras aos filhos é uma prática condenada pela maioria dos genitores (57\%). Não transmitir valores morais (39\%), não dar acesso à educação informal (29\%), não ensinar a criança a ser obediente $(25 \%)$, independente $(11 \%)$ e competitiva (7\%), não demonstrar afeto (22\%), não proporcionar uma boa relação genitores-criança (18\%), não dar suporte emocional (7\%), não manter um bom relacionamento conjugal $(7 \%)$ e não facilitar o acesso à educação formal (7\%) são todas formas inadequadas de educar filhos, de acordo com os entrevistados.

Para alguns genitores de classe média, não ensinar os filhos a se tornarem independentes (21\%) e competitivos (14\%) constitui uma grande falha na educação, embora nenhum genitor de classe baixa tenha mencionado tais valores. A maioria dos genitores desta classe social $(71 \%)$ considera inadequada uma educação de filhos em que não haja a transmissão de valores morais, opinião expressa por apenas um $(7 \%)$ pai de classe média. Comparando os relatos de pais e mães, verificou-se que, para alguns pais (29\%), não manter um bom relacionamento com as crianças pode ser prejudicial a elas, mas somente $7 \%$ das mães pensam de forma semelhante; para estas (43\%), não ensinar os filhos a serem obedientes é uma prática inadequada, enquanto que apenas 7\% dos pais consideram esta questão importante.

Mães e pais concordam ou discordam acerca da educação de seus filhos?

Os cônjuges concordam que é necessário dar acesso à educação formal (57\%), orientar e disciplinar as crianças (57\%), ser afetivo e prestar suporte emocional (21\%), manter um bom relacionamento familiar $(21 \%)$ e prover o sustento material (7\%) para os fillhos. Quanto ao papel dos filhos, alguns casais concordam (18\%) sobre a necessidade de os filhos terem independência emocional e financeira e serem honestos, responsáveis e respeitadores, além de possuírem valores morais e religiosos $(11 \%)$.

As discordâncias entre os cônjuges referem-se às estratégias de socialização $(75 \%)$ e às práticas parentais relativas à alimentação $(7 \%)$ dos filhos. A punição física e/ou verbal das crianças, exercidas com excesso de rigidez ou de flexibilidade (46\%), e o oferecimento de reforçadores primários aos filhos, como presentes e doces $(21 \%)$ constituem os principais motivos de discordâncias. De um total de 28 entrevistados, cinco relataram não existir divergências entre eles e seus respectivos cônjuges sobre a educação de seus filhos.

\section{As Relações Conjugais}

Como os casais percebem a ligação com seus parceiros?

À questão "Você acha que você e seu(sua) esposo(a) combinam um com o outro de modo a formarem um 'casal de verdade?', a maioria dos cônjuges $(82 \%)$ respondeu que formam uma unidade com seus respectivos parceiros; $11 \%$ consideram que não têm ligação com seus cônjuges a ponto de se perceberem como uma díade integrada; e 7\% disseram que, às vezes, combinam com seus(suas) esposos(as) e, às vezes, não. Dentre os que responderam positivamente à pergunta, 30\% consideram a coalizão completa ou total e $70 \%$ acham que existe afinidade entre eles e seus companheiros, porém, não em sua totalidade. A maioria das mães $(86 \%)$ e dos pais $(79 \%)$ acredita que existe coalizão marital entre eles e seus respectivos parceiros.

\begin{tabular}{|c|c|c|c|}
\hline 而 afetividade & 目bondade & 图 suporte emocional & 四 honestidade \\
\hline submissão & participação & 图 suporte material & 冈 responsável filhos/tarefas \\
\hline$\square$ disciplina & 圖 orientação & & \\
\hline
\end{tabular}

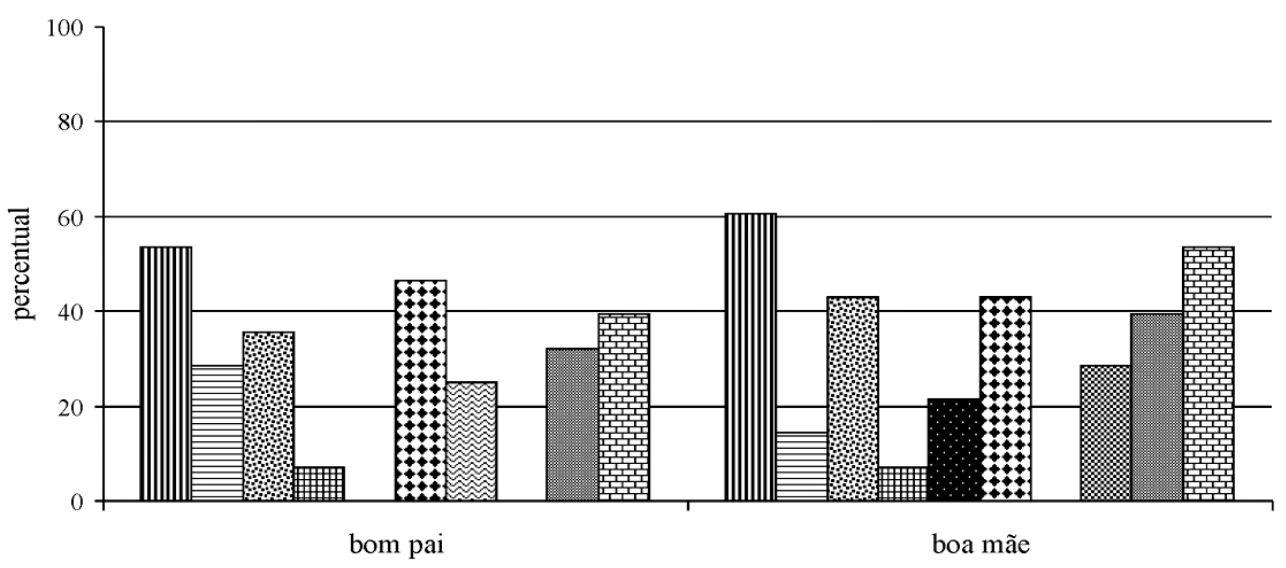

Figura 3. Valores sobre o que é ser um 'bom' pai e uma 'boa' mãe. 
Os casais estão satisfeitos ou insatisfeitos com suas relações conjugais?

A maioria dos cônjuges está satisfeita com seus relacionamentos maritais e os consideram bons ou ótimos $(75 \%)$, embora, para 18\% deles, as relações sejam consideradas regulares. Há mais cônjuges de classe média $(79 \%)$ satisfeitos com suas relações maritais que de classe baixa (64\%). Um maior número de entrevistados da classe baixa (29\%) considera suas relações regulares ou médias, comparados aos de classe média (7\%).

Os cônjuges consideram-se satisfeitos, primeiramente, por haver compromisso, respeito e envolvimento em suas relações $(55 \%)$; depois pela intimidade (40\%), ou seja, cumplicidade, confiança mútua, possibilidade de auto-revelação, confidência; e também pela similaridade $(40 \%)$ ou homogeneidade de objetivos, pensamentos, valores e práticas existentes entre o casal. Os cônjuges de classe média explicam a sua satisfação no casamento com base no compromisso $(82 \%)$, na intimidade (64\%), na similaridade (54\%), nas trocas afetivas (45\%) e na negociação (45\%). Já os de classe baixa pela ausência de conflitos e brigas (55\%) entre o casal.

A responsabilidade pela satisfação ou insatisfação conjugal foi atribuída aos próprios membros do subsistema conjugal, de acordo com a maioria dos entrevistados $(86 \%)$. Todos os de classe média e $71 \%$ dos de classe baixa acreditam que o marido e a esposa, juntos, contribuem para a qualidade da relação marital. A qualidade do relacionamento marital também foi atribuída a outros membros familiares (14\%), tais como os filhos e os genitores do respondente, e a fatores externos à família (14\%), destacando 'Deus' como o principal responsável.

\section{O que é considerado positivo e o que incomoda no relacionamento conjugal?}

Os pontos positivos relatados referem-se a dimensões de qualidade da própria relação conjugal $(71 \%)$, tais como intimidade, trocas afetivas, compromisso, respeito e envolvimento. Além destes, foram relatados os seguintes aspectos: negociação e equilibrio nas concessões mútuas $(25 \%)$, similaridade de objetivos, pensamentos, valores e práticas (14\%); ausência de conflitos, brigas e/ou ciúmes $(11 \%)$; e satisfação nas relações sexuais (4\%). Características comportamentais e de personalidade positivas do cônjuge foram relatadas por $14 \%$ dos entrevistados. As diferenças no relato de pais e mães e entre as classes sociais podem ser observadas na Figura 4.

A maioria dos cônjuges $(75 \%)$ sente-se incomodada com aspectos pessoais do companheiro (50\%), com aspectos específicos do relacionamento familiar e social (21\%), com a divisão de trabalho doméstico estabelecida pelo casal $(11 \%)$, com o tipo de relacionamento sexual $(7 \%)$ e com a forma de administrar o orçamento familiar (7\%). Para o restante dos entrevistados (25\%), a maioria deles de classe baixa, nada incomoda na sua relação conjugal.

O que acontece quando os casais se desentendem e por quanto tempo eles acreditam que seu casamento vai durar?

Quando ocorre atrito entre o casal, os cônjuges reagem de forma negativa ou positiva. A maioria dos casais $(83 \%)$ apresenta reações negativas nestas ocasiões: discute de forma exaltada, gritando ou reclamando $(79 \%)$, e demonstra afetos negativos $(50 \%)$, como raiva, aborrecimento, nervosismo, com um ou ambos os cônjuges se retraindo (68\%), permanecendo sem conversar por algum tempo. O diálogo foi a única reação considerada positiva dentre as respostas mencionadas pelos entrevistados, com poucos casais $(32 \%)$ relatando procurar dialogar e conversar sobre o assunto ou a situação que provoca conflito, visando encontrar consenso ou, pelo menos, amenizar a dificuldade momentânea. Ao invés do diálogo, preferem o isolamento.

A respeito da existência de agressões físicas e/ou verbais durante as discussões, a maioria dos casais (57\%) relatou que, às vezes, eles se agridem mutuamente e/ou falam palavras que magoam um ao outro, mas apenas verbalmente. As agressões verbais e físicas conjugadas foram mencionadas somente por uma mãe de classe baixa. Dos entrevistados de classe média, 67\% relataram não haver agressões entre eles e seus cônjuges, em contraposição a 33\% dos de classe baixa. As diferenças no relato de pais e mães e entre as classes sociais, no que tange às reações dos cônjuges em situações de conflito, são mostradas na Figura 5.

Os entrevistados acreditam que seus casamentos vão durar para sempre/eternamente $(54 \%)$, por muito tempo (14\%) ou por pouco tempo $(4 \%)$, ou se estenderão, caso o respondente, seu cônjuge ou

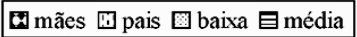

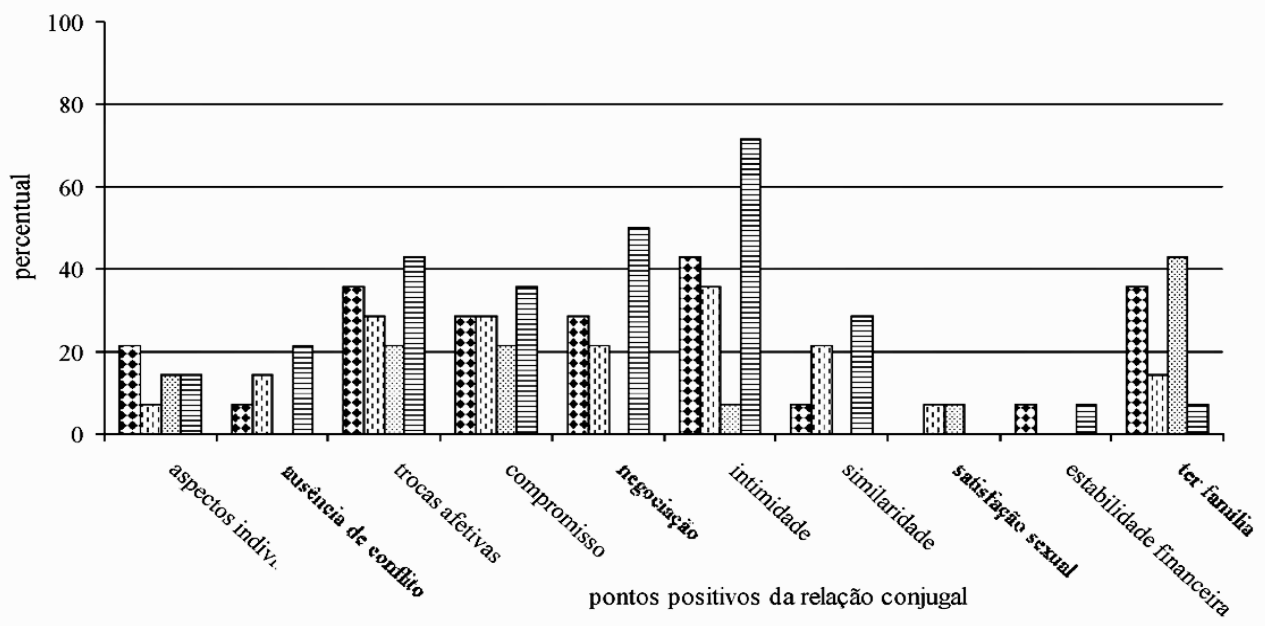

Figura 4. Pontos positivos da relação conjugal, segundo o relato de pais e mães de classes média e baixa. 


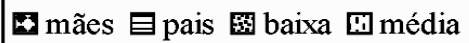

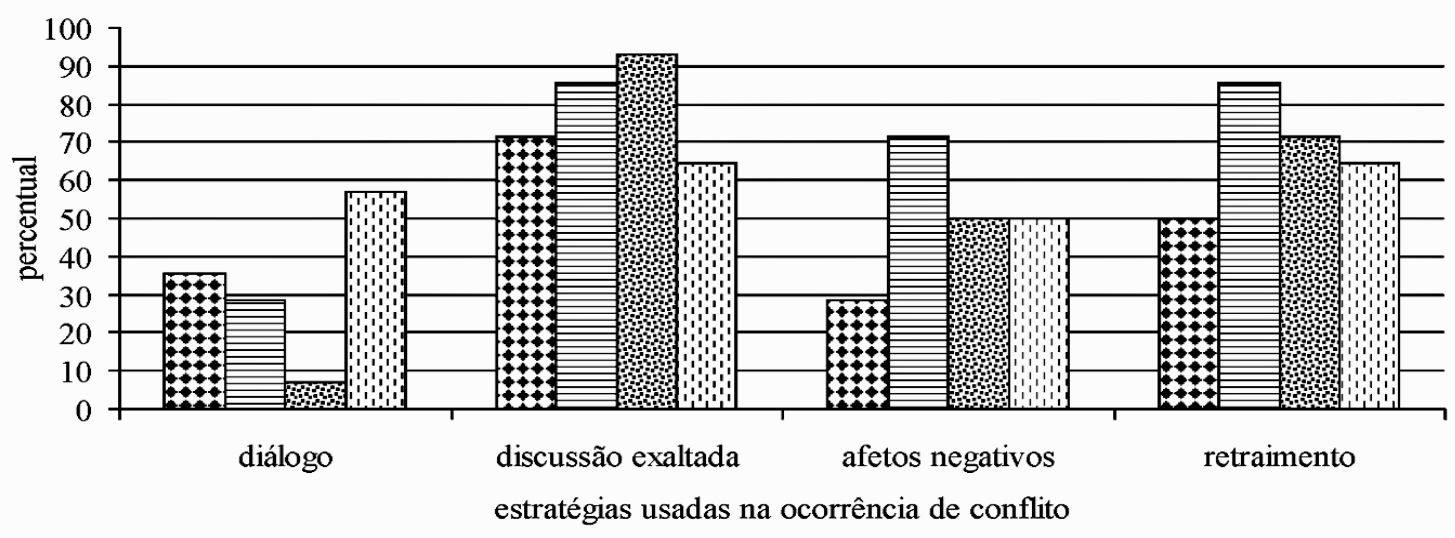

Figura 5. Reações dos cônjuges durante o conflito conjugal, segundo o relato de mães e pais de classes baixa e média.

ambos mantenham o mesmo tipo de relacionamento presente (11\%). Entretanto, 18\% dos entrevistados, a maioria deles de classe baixa, não souberam precisar o tempo que seus casamentos durariam. É interessante destacar que a durabilidade eterna do casamento foi mais relatada por cônjuges de classe média que de classe baixa e mais por mães que por pais.

\section{Qual é a concepsão de casamento para os cônjuges?}

Todos os cônjuges acreditam que o casamento seja uma união ou uma relação entre duas pessoas. Quarenta e dois porcento (42\%) dos entrevistados justificam esta união pelo objetivo de constituir uma familia e ter filhos em comum. A esta idéia de casamento, eles associam outros fatores relativos à qualidade da relação como: trocas afetivas $(43 \%)$, similaridade $(43 \%)$, compromisso $(36 \%)$, negociação e equilíbrio nas concessões mútuas $(36 \%)$, intimidade $(21 \%)$, durabilidade (18\%), submissão ao outro $(7 \%)$, presença de conflitos $(7 \%)$ e admiração pelo outro (4\%). Os pais definiram o casamento pelas trocas afetivas $(50 \%)$, similaridade $(50 \%)$, negociação e equilibrio nas concessões mútuas (43\%) e pelo compromisso (43\%), enquanto as mães enfatizaram as trocas afetivas $(36 \%)$ e a similaridade $(36 \%)$. Para os integrantes da classe média, o significado do casamento está associado, principalmente, à similaridade (64\%), à capacidade de negociação $(50 \%)$, ao compromisso $(43 \%)$ e às trocas afetivas $(43 \%)$. Para os cônjuges de classe baixa, as trocas afetivas $(43 \%)$ constituem o principal aspecto relacionado à idéia de casamento.

O que faz um casamento ser bem sucedido e durar muito tempo? Segundo os cônjuges, três grandes fatores levam ao sucesso do casamento e permitem que ele dure muito tempo: a qualidade das relações conjugais $(100 \%)$, aspectos do sistema familiar $(25 \%)$ e características positivas do indivíduo $(18 \%)$. Dentre os fatores relativos à relação conjugal, foram destacados: a negociação e o equilibrio nas concessões mútuas $(79 \%)$, a similaridade (64\%), a intimidade (57\%), o compromisso ( $46 \%$ ), a fidelidade (43\%), as trocas afetivas $(39 \%)$ e relações sexuais satisfatórias (11\%). Foram mencionadas as seguintes dimensões internas e externas ao sistema familiar que dão suporte a um casamento bem-sucedido: a existência de filhos (14\%), a religiosidade $(7 \%)$, a manutenção de um equilibrio entre trabalho e familia $(7 \%)$ e a estabilidade financeira (4\%). Dentre as características individuais que favorecem a relação marital e sua durabilidade, foram destacadas: a flexibilidade $(18 \%)$, a perseverança $(11 \%)$, a capacidade de perdoar $(7 \%)$ e a capacidade de inovar e dinamizar a rotina conjugal $(7 \%)$. Para a maioria dos casais de classe média e baixa, o sucesso do casamento está baseado em negociação e equilibrio nas concessões mútuas e na intimidade.

$\mathrm{O}$ que faz um casamento ser mal-sucedido e durar pouco? $\mathrm{O}$ insucesso e o término do casamento foram associados, também, às dimensões das relações conjugais $(96 \%)$, do indivíduo $(43 \%)$ e do sistema familiar (14\%). A ausência de negociação (71\%), de similaridade $(57 \%)$, de fidelidade $(32 \%)$, de trocas afetivas $(25 \%)$, de respeito $(21 \%)$ e de liberdade (7\%) são aspectos da relação conjugal que levam ao fracasso e ao término das relações maritais, de acordo com os entrevistados. Já dentre as características individuais, destacamse: inflexibilidade (43\%), ser desonesto e mentiroso (11\%), passividade (4\%) e cultivar vícios (4\%). Aspectos do sistema familiar, como a falta de equilibrio entre as relações de amizade e a família e/ou entre o trabalho e a familia (21\%), a falta de estabilidade financeira (11\%) e conflitos e desavenças com a famillia de origem e do cônjuge (4\%) também foram mencionados. Os casais pertencentes à classe média acreditam que a falta de similaridade $(79 \%)$ e de valores e crenças $(50 \%)$ em comum e a ausência de negociação (71\%) entre os cônjuges são os principais aspectos que levam ao fracasso e ao fim do casamento. Para os casais de classe baixa, a incapacidade de negociação (71\%) e a presença de agressões físicas e verbais (43\%) constituem os principais fatores que levam ao término do casamento.

Mas, o que pensam os pais e as mães de nosso estudo sobre aspectos relativos às inter-relações entre as relações parentais e maritais? A seguir, apresentamos as suas opiniões a respeito da interferência dos filhos na relação conjugal e desta nas relações parentais.

\section{As Inter-relações entre as Relações Maritais e Parentais Os filhos interferem na relacão marital?}

Na opinião de 54\% dos entrevistados, os filhos interferem na sua relação conjugal, embora, para $46 \%$, eles em nada interferem. A interferência no relacionamento do casal foi considerada tanto positiva (53\%), como negativa (47\%). Por exemplo:

Eles interfere. Bem. Ah, eles ajuda muito o casal, filho ajuda muito o casal. A viver feliz assim, o casal com os filho. Quando num tem 
filho, quando o marido vai trabalhar, a gente fica sozinha e quando já tem filho, fica com os filho em casa. Porque quando a gente fica só os dois e quando tem filho, aí, fica o pai, a mãe e os filho junto. Eé bem melhor. (mãe de classe pobre)

Se for considerar interferência, considero como positiva, porque eles traduzem um presente, muita felicidade, muita alegria e eles completam a nossa felicidade. (mãe de classe média)

Veja bem, eu acho que, muitas vezes, a mulher, ela... até eu acho que ela tem um certo ciúmes, né? Que, muitas vezes, o marido dá mais atenção aos filhos do que à própria esposa... Então, interfere, muitas vezes, é isso aí. Que ela é ciumenta até com os filho, comigo e tal, mas a gente releva isso aí e vai levando. (pai de classe baixa)

... Às vezes, sim, mas num interferem que eu digo assim, às vezes, eles é... às vezes, tem que dar mais atenção, esquece mais o nosso lado de casal pra dar mais atenção pra eles como filhos, no relacionamento dos pais com os filhos, mas... (pai de classe média)

Dentre os cônjuges que relataram sofrer interferências negativas, $71 \%$ compartilhavam da idéia de que deveriam adotar estratégias para manter a privacidade do casal e para equilibrar a atenção entre o cônjuge e os filhos, em contraposição a $27 \%$ que achavam que não poderiam fazer nada, pois os filhos ainda eram pequenos $\mathrm{e}$ necessitavam da atenção dos genitores. A maioria dos genitores de classe média $(71 \%)$ relatou sofrer interferência dos filhos na relação marital, tanto positiva (40\%) como negativa (60\%). No entanto, para a maioria dos cônjuges de classe baixa (64\%) não existia influência dos filhos em seus casamentos e, dos que percebiam a interferência filial (36\%), somente um pai a classificou negativamente. A interferência dos filhos é percebida por mães (50\%) e pais (57\%) de modo diferente. Enquanto a maioria das mães percebe a interferência como positiva, para os pais ela é negativa.

\section{$O$ relacionamento do casal interfere nas relações parentais?}

A maioria dos cônjuges (86\%) acreditava que as suas relações maritais influenciavam o seu relacionamento com os filhos, tanto de forma direta, como indireta. A influência direta ocorria de quatro formas: a) através das práticas educativas utilizadas pelos genitores com seus filhos (54\%); b) pela transmissão de amor e segurança aos filhos, quando a relação conjugal era boa $(27 \%)$; c) no engajamento conjunto em atividades de educação e cuidado dos filhos, quando predominava o bom relacionamento marital (25\%); e, d) pela transmissão de sentimentos negativos aos filhos, quando as relações conjugais eram ruins (18\%).

A influência indireta foi associada à qualidade da relação conjugal, isto é, boa ou ruim. Por exemplo, quando o relacionamento do casal é bom, os cônjuges acreditam que o diálogo entre eles sobre aspectos do desenvolvimento e educação de filhos contribui para torná-los mães e pais mais tranqüilos e adequados, melhorando, assim, a qualidade da relação parental (32\%). Um relacionamento marital ruim favorece a emergência de discordâncias, principalmente quanto a aspectos do desenvolvimento e da educação dos filhos, o que causa estresse e irritação em mães e pais, piorando a qualidade da relação genitores-criança (7\%). A maioria dos cônjuges de classe média e baixa concorda que o bom relacionamento conjugal transmite amor e segurança aos filhos e influencia diretamente as relações parentais, particularmente no que tange às práticas educativas. Por exemplo:

... Eu acho o seguinte, se você tem um marido compreensivo, o resto tudo flui, tudo flui, cê não sente dificuldade em nada, cê tem um apoio, então, isso aí, deixa a mulher mais segura... em educar os filhos, você não fica agressiva com os filhos, porque cê tá bem com o marido, cê tando bem com o marido, cê tá bem com os filhos, tá bem com todo mundo, mas se você briga com o marido, aí, cê tá ruim com todo mundo, às vezes, cê num quer nem ver ninguém na frente, né? (mãe de classe média)

... Melhora. Melhora no educar os filhos, nisso tudo melhora. Ajuda. Ah, ajuda que, às vezes, eu faço alguma coisa, ela (esposa) vai e corrige, a G. diz: 'Não, num é assim, tem que ser assim', então, isso tudo ajuda. (pai de classe baixa)

\section{Os casais estão satisfeitos com sua vida em família e com seus filhos?}

A maioria dos cônjuges está satisfeita e feliz com sua criança ( $96 \%$ ), com seus outros filhos ( $96 \%$ ) e com sua vida em familia (79\%), embora os cônjuges de classe baixa $(27 \%)$ estejam mais insatisfeitos com a vida em família que os de classe média (14\%). A satisfação dos genitores de classe média com a criança alvo decorre, principalmente, das características emocionais (64\%) e comportamentais $(57 \%)$ positivas da criança. Para a classe baixa, são o bom comportamento (79\%) e as características físicas e de saúde satisfatórias (43\%) da criança são mais importantes.

Os cônjuges insatisfeitos com a vida familiar sentem-se assim pela falta de estabilidade financeira (11\%), pela ausência de contato com parentes consangüíneos ou pelo excesso de contato com parentes do cônjuge $(7 \%)$, ou, ainda, por não existir uma boa relação marital (4\%). A insatisfação relativa à criança alvo e aos outros filhos foi associada a características dos próprios genitores, como a sua preocupação com o bem-estar dos filhos $(7 \%)$ e às dificuldades pessoais em lidar com os próprios filhos (4\%).

\section{Discussão}

As familias de ambas as classes sociais apresentam similaridades, mas, sobretudo, diferenças quanto aos modos de vida, ao desenvolvimento dos filhos, às relações parentais e às relações conjugais, de acordo com o relato dos genitores. Essas diferenças, provavelmente, decorrem de valores distintos acerca de cada um destes aspectos e de suas visões de mundo vinculadas ao contexto social, econômico, histórico e cultural no qual as familias estão inseridas (Bronfenbrenner, 1999; Hinde, 1997; Romanelli, 1998). Os resultados de nosso estudo mostram especificidades que são próprias do contexto de vida das famillias de ambas as classes sociais. Por exemplo, o acesso à informação especializada sobre a educação de filhos, como livros, revistas e profissionais que lidam com crianças, que fazem parte mais do cotidiano de famílias de classe média (Simionato-Tozo \& Biasoli-Alves, 1998) que de familias de classe baixa, influenciam os valores e as crenças dos genitores.

Em relação às diferenças quanto aos valores associados à educação de filhos, a classe média considera mais importante transmitir valores relativos à sociabilidade è afetividade, enquanto a classe baixa enfatiza 
a educação formal, o respeito e os valores morais. Tais orientações distintas sobre o que deve ser ensinado às crianças são coerentes com a literatura e dependem do status social e do que é esperado dos filhos no futuro (Kohn, 1979; Luster, Rhoades \& Haas, 1989; Tudge \& cols., 1999).

Os pais desempenham diferentes papéis em função do contexto cultural no qual estão inseridos e estes papéis são multidimensionais e complexos. Segundo Lewis e Dessen (1999), o pai tradicional é aquele que centra suas atividades no mundo do trabalho, havendo pouco engajamento no cuidado dos filhos; o pai moderno está envolvido no desenvolvimento dos filhos, mas enfatiza o papel sexual, o desempenho acadêmico e o desenvolvimento moral; e o pai emergente é aquele que compartilha de forma mais igualitária as tarefas de cuidados dos filhos. Os dados relativos à divisão de trabalho doméstico, aos valores enfatizados pelos pais na educação de suas crianças e às idéias que os genitores têm sobre um pai ideal nos levam a crer que o perfil do pai presente nas familias deste estudo é um misto do pai tradicional com o pai moderno, ainda não tendo sido absorvidas as características do pai emergente.

Os dados a respeito do pai e mãe ideais refletem a concepção tradicional dos papéis de mãe e pai em nossa cultura, que ainda perduram, apesar das grandes transformações sofridas na sociedade e nas familias brasileiras, nas últimas décadas (Dessen \& Torres, 2002). No entanto, as diferenças nos relatos de pais e mães quanto aos valores a serem transmitidos aos filhos, ao emprego de estratégias de socialização, ao que seria uma educação adequada e inadequada, dentre outros, denotam um movimento em direção às transformações do papel paterno, conforme sugerido por Lewis e Dessen (1999), embora as mães continuem contribuindo para a manutenção dos mesmos. Portanto, é necessário que outras pesquisas investiguem as diferenças nos papéis de mães e pais brasileiros levando em consideração as diferentes classes sociais e as diferentes regiões brasileiras, dada a sua diversidade cultural (Dessen \& Torres, 2002).

A maioria dos casais estava satisfeita com sua relação conjugal, sendo ambos, o marido e a esposa, os principais responsáveis pela satisfação ou insatisfação no casamento. Entretanto, havia mais cônjuges de classe média satisfeitos que de classe baixa, o que é consistente com a literatura (Berscheid, 1994; Berscheid \& Reis, 1998; Fletcher, Simpson, Thomas \& Giles, 1999; Gottman, 1993, 1998; Hinde, 1997), que afirma que os casais de classe média tendem a idealizar mais o seu casamento. Além disso, os valores associados ao casamento, diferentes em ambas as classes sociais, também conduzem a percepções diferenciadas sobre a satisfação no casamento. Portanto, é necessário investigar os valores e as crenças associados ao casamento e à familia brasileira, para que possamos compreender melhor as relações conjugais em nosso contexto cultural e, conseqüentemente, as relações parentais.

De acordo com Gottman (1998) e Gottman e Silver (1999), os casais felizes engajam-se em interações mais construtivas, com reciprocidade positiva e capacidade de entendimento e respeito mútuo, enquanto que nos relacionamentos infelizes predominam as interações conflituosas, com comportamentos negativos e retraimento do casal. Os relatos dos casais de nosso estudo confirmam os dados desses autores, particularmente no que tange às reações dos casais em situações de conflito. Outro dado a ser destacado é o fato de que o parceiro, em geral, atribui a responsabilidade pelo mau funcionamento das relações conjugais ao outro parceiro, isto é, o que não está suficientemente bom e agradável no casamento é 'responsabilidade' do outro parceiro e não sua. Estes dados sustentam as idéias de Hinde (1997) e de Gottman e Silver de que pensamentos e sentimentos negativos recíprocos são comuns em todos os casais, mas, nos relacionamentos infelizes, eles são a característica básica e dominam os sentimentos e pensamentos positivos. Segundo Gottman, os casais insatisfeitos consideram aproximadamente todo traço negativo como característica de seus parceiros, enquanto que os felizes consideram os traços positivos característicos de seus parceiros.

Para os casais, os aspectos positivos do casamento são a intimidade, as trocas afetivas, o compromisso, o respeito e o envolvimento na relação conjugal, a negociação e o equilibrio nas concessões mútuas, a similaridade de objetivos, pensamentos, valores e práticas, a ausência de conflitos, brigas e ciúmes e a satisfação nas relações sexuais. Os cônjuges, independente de classe social e sexo, têm uma visão similar acerca do que pode levar as relações íntimas a serem bem ou mal sucedidas, isto é, presença ou ausência de negociação e de similaridade, respectivamente. Portanto, o que sustenta um casamento satisfatório é a capacidade de os parceiros entrarem em acordo e cederem diante de situações conflituosas e, também, o fato de eles possuírem características em comum. Esses dados são coerentes com aqueles obtidos por Gottman $(1993,1998)$ e Gottman e Silver (1999). No entanto, há diferenças entre as classes sociais, quanto aos valores atribuídos ao casamento. Enquanto os casais de classe baixa tendem a valorizar mais a constituição de uma familia como o fator preponderante de um casamento, os cônjuges de classe média tendem a valorizar, primeiramente, aspectos relativos à relação conjugal, demonstrando absorver mais as novas tendências a respeito do conceito de família e casamento (Hodkin, Vacheresse \& Buffett, 1996; Petzold, 1996).

A maioria dos cônjuges acredita que o seu relacionamento influencia as relações genitores-criança de forma direta e indireta, e que os filhos interferem em suas relações maritais, o que vem sendo salientado pela literatura (Belsky, 1984; Bigras \& Paquette, 2000; Bond \& McMahon, 1984; Collins, Maccoby, Steinberg, Hetherington \& Bornstein, 2000; Deal \& cols., 1999; Gottman \& Levenson, 1992; Gottman \& Silver, 1999; Kreppner, 1995, 2000; Kreppner \& Ullrich, 1998). Portanto, é fundamental que os pesquisadores considerem, na implementação de seus estudos, a influência e a interdependência entre os membros familiares, em seus diferentes papéis (de esposa e mãe, de marido e pai), e também entre os subsistemas familiares, conjugal e parental. Não podemos mais negar a complexidade de tais influências e suas conseqüências para o desenvolvimento infantil em nossos projetos de pesquisa, o que seria, retardar o avanço do conhecimento sobre as relações familiares. Além disto, do ponto de vista clínico, os esforços para aumentar a qualidade das relações parentais podem ser acentuados se forem dirigidos às dificuldades maritais.

\section{Referências}

Belsky, J. (1981). Early human experience: A family perspective. Developmental Psychology, 17, 3-23.

Belsky, J. (1984). The determinants of parenting: A process model. Child Development, 55, 83-96.

Psicologia: Reflexão e Crítica, 2005, 18(2), pp.151-161 
Berscheid, E. (1994). Interpersonal relationships. Annual Review of Psychology, 45, 79-129.

Berscheid, E. \& Reis, H. T. (1998). Attraction and close relationships. Em D. T. Gilbert, S. T. Fiske \& G. Lindzey (Orgs.), The handbook of social psychology (Vol. II; pp. 193-281). New York: Oxford University Press.

Bigras, M. \& Paquette, D. (2000). L’ Interdépendance entre les sous-systèmes conjugal et parental: Une analyse personne-processus-contexte. Psicologia: Teoria e Pesquisa, 16, 91-102.

Bond, C. R. \& McMahon, R. J. (1984). Relationships between marital distress and child behavior problems, maternal personal adjustment, maternal personality, and maternal parenting behavior. Journal of Abnormal Psychology, 93, 348-351.

Braz, M. P. (2002). As relacōes conjugais e parentais de familias com criancas pré-escolares: Uma comparação do relato de pais e mães de classes sociais baixa e média. Dissertação de Mestrado não-publicada, Instituto de Psicologia, Universidade de Brasilia. Brasilia, DF.

Bronfenbrenner, U. (1999). Environments in developmental perspective: Theoretical and operational models. Em S. L. Friedman \& T. D. Wachs (Orgs.), Measuring environment across the life span: Emerging methods and concepts (pp. 328).Washington, DC: American Psychological Association.

Brody, G. H., Pellegrini, A. D. \& Sigel, I. E. (1986). Marital quality and mother-child and father-child interactions with school-aged children. Developmental Psychology, 22, 291-296.

Carter, B. \& McGoldrick, M. (1995). As mudanças no ciclo de vida familiar: Uma estrutura para a terapia familiar (M. A. V. Veronese, Trad.). Em B. Carter \& M. McGoldrick (Orgs.), As mudanças no ciclo de vida familiar (pp. 7-29). Porto Alegre: Artes Médicas. (Original publicado em 1980)

Collins, W. A., Maccoby, E. E., Steinberg, L., Hetherington, E. M. \& Bornstein, M. H. (2000). Contemporary research on parenting: The case for nature and nurture. American Psychologist, 55, 218-232.

Cox, M. J., Owen, M. T., Lewis, J. M. \& Henderson, V. K. (1989). Marriage, adult adjustment, and early parenting. Child Development, 60, 1015-1024.

Deal, J. E., Hagan, M. S., Bass, B., Hetherington, E. M. \& Clingempeel, G. (1999). Marital interaction in dyadic and triadic contexts: Continuities and discontinuities. Family Process, 38,105-115.

Dessen, M. A. (1999). Questionário de caracterização do sistema familiar. Manuscrito não-publicado, Laboratório de Desenvolvimento Familiar, Instituto de Psicologia da Universidade de Brasília. Brasília, DF.

Dessen, M. A. \& Torres, C. V. (2002). Family and socialization factors in Brazil: An overview. Em W. J. Lonner, D. L. Dinnel, S. A. Hayes \& D. N. Sattler (Orgs.), Online Readings in Psychology and Culture (Unit 13, Chapter 2), (bttp:// wnnv.nnn.edu/ culture), Center for Cross-Cultural Research, Western Washington University, Bellingham, Washington, USA.

Emery, R. E. (1982). Interparental conflict and the children of discord and divorce. Psychological Bulletin, 92, 310-330.

Emery, R. E., Fincham, S. D. \& Cummings, E. M. (1992). Parenting in context: Systematic thinking about parental conflict and its influence on children. Journal of Consulting and Clinical Psychology, 60, 909-912.

Erel, O. \& Burman, B. (1995). Interrelatedness of marital relations and parent-child relations: A meta-analytic review. Psychological Bulletin, 118, 108-132.

Féres-Carneiro, T. (1998). Casamento contemporâneo: O difícil convívio da individualidade com a conjugalidade. Psicologia: Reflexão e Crítica, 11, 379-394.

Fletcher, G. J. O., Simpson, J. A., Thomas, G. \& Giles, L. (1999). Ideals in intimate relationships. Journal of Personality and Social Psychology, 76, 72-89.

Goldberg, W. A. \& Easterbrooks, M. A. (1984). The role of marital quality in toddler development. Developmental Psychology, 20, 504-514.

Gottman, J. M. (1993). The roles of conflict engagement, escalation, and avoidance in marital interaction: A longitudinal view of five types of couples. Journal of Consulting and Clinical Psychology, 61, 06-15.

Gottman, J. M. (1998). Psychology and the study of marital processes. Annual Review of Psychology, 49, 169-197.

Gottman, J. M. \& Katz, L. F. (1989). Effects of marital discord on young children's peer interaction and health. Developmental Psychology, 25, 373-381.
Gottman, J. M. \& Levenson, R. W. (1992). Marital processes predictive of later dissolution: Behavior, physiology, and health. Journal of Personality and Social Psychology, 63, 221-233.

Gottman, J. M. \& Silver, N. (1999). Sete princípios para o casamento dar certo. Rio de Janeiro: Objetiva.

Grych, J. H. \& Fincham, F. D. (1990). Marital conflict and children's adjustment: A cognitive-contextual framework. Psychological Bulletin, 108, 267-290.

Heavey, C. L., Shenk, J. L. \& Christensen, A. (1994). Marital conflict and divorce: A developmental family psychology perspective. Em L. L'Abate (Org.), Handbook of developmental family psychology and psychopathology (pp. 221-242). New York: Wiley \& Sons.

Hinde, R. A. (1997). Relationships: A dialeticalperspective. London: Psychology Press. Hodkin, B., Vacheresse, A. \& Buffett, S. (1996). Concept of family: Methodological issues in assessing perceived family membership. Em M. Cusinato (Org.), Research on family: Resources and needs across the world (pp. 45-54). Milão: LEDEdicioni Universitarie.

Kohn, M. L. (1979). The effects of social class on parental values and practices. Em D. Reiss \& H. A. Hoffman (Orgs.), The american family: Dying or developing (pp. 45-68). New York: Plenum Press.

Kreppner, K. (1995). Padrões comportamentais da família perante um segundo filho. Em J. Gomes-Pedro \& M. F. Patricio (Orgs.), Bebé XXI: Criança e família na viragem do século (pp. 431-463). Lisboa: Fundação Calouste Gulbenkian.

Kreppner, K. (2000). The child and the family: Interdependence in developmental pathways. Psicologia: Teoria e Pesquisa, 16, 11-22.

Kreppner, K. \& Ullrich, M. (1998). Talk to mom and dad, and listen to what is in between. Em M. Hofer, P. Noack \& J. Youniss (Orgs.), Verbal interaction and development in familis with adolescentes (pp. 83-108). Greenwich, C.T.: Ablex.

Lee, C. M. \& Gotlib, I. H. (1994). Mental illness and the family. Em L. L'Abate (Org.), Handbook of developmental family psychology and psychopathology (pp. 243263). New York: Wiley \& Sons.

Lewis, C. \& Dessen, M. A. (1999). O pai no contexto familiar. Psicologia: Teoria e Pesquisa, 15, 9-16.

Luster, T., Rhoades, K. \& Haas, B. (1989). The relation between parental values and parenting behavior: A test of the Kohn hypothesis. Journal of Marriage and the Family, 51, 139-147.

Petzold, M. (1996). The psychological definition of "the family". Em M. Cusinato (Org.), Research on family: Resources and needs across the world (pp. 25-44). Milão: LED-Edicioni Universitarie.

Radke-Yarrow, M., Richters, J. \& Wilson, W. E. (1988). Child development in a network of relationships. Em R. Hinde \& J. Stevenson-Hinde (Orgs.), Relationships within families: Mutual influences (pp. 48-67). Oxford: Clarendon Press \& University Press.

Romanelli, G. (1998). O relacionamento entre pais e filhos em famílias de camadas médias. Paidéia: Cadernos de Psicologia e Educacão, 8, 123-136.

Simionato-Tozo, S. M. P. \& Biasoli-Alves, Z. M. M. (1998). O cotidiano e as relações familiares em duas gerações. Paidéia: Cadernos de Psicologia e Educacãõo, 8, 137-150.

Siqueira, R. C., Ribeiro, M. B. \& Duarte, W. F. (1999). Transformações observadas nas relações do casal com o nascimento do primeiro filho [Resumo]. Em Anais do II Encontro de Psicologia Clinica da Universidade Presbiteriana Mackenrie (pp. 311-317). São Paulo: Universidade Presbiteriana Mackenzie.

Sroufe, L. A. \& Fleeson, J. (1988). The coherence of family relationships. Em R. Hinde \& J. Stevenson-Hinde (Orgs.), Relationships within families: Mutual influences (pp. 27-47). Oxford: Oxford University Press.

Tudge, J., Hogan, D., Lee, S., Tammeveski, M. M., Kulakova, N., Snezhkova, I. \& Putnam, S. (1999). Cultural heterogeneity: Parental values and beliefs and their preschoolers' activities in the United States, South Korea, Russia, and Estonia. Em A. Göncü (Org.), Children's engagement in the world: Sociocultural perspectives (pp. 62-96). London: Cambridge University Press.

Recebido: 18/11/2003

$1^{a}$ Revisão: $26 / 03 / 2004$

Aceite Final: 05/04/2004

Sobre as autoras

Marcela Pereira Braz é Mestre em Psicologia pela Universidade de Brasilia.

Maria Auxiliadora Dessen é Psicóloga, Mestre em Psicologia pela Universidade de Brasilia, Doutora em Psicologia pela Universidade de São Paulo, Pósdoutora pela University of L ancaster (Inglaterra) e pelo Max Planck Institute for Human Development (Alemanha). É Professora da Universidade de Brasilia.

Nara Liana Pereira Silva é Psicóloga, Mestre e Doutora em Psicologia pela Universidade de Brasilia. 